\title{
Reproductive exocrine and endocrine profile of female langur monkeys, Presbytis entellus
}

\author{
N. K. Lohiya, R. S. Sharma, C. P. Puri*, G. F. X. David $\dagger$ and \\ T. C. Anand Kumar* \\ Reproductive Physiology Section, Department of Zoology, University of Rajasthan, Jaipur-302 004; \\ *Institute for Research in Reproduction, Parel, Bombay-400 012; and $\dagger$ Department of Anatomy, \\ All India Institute of Medical Sciences, New Delhi-110 029, India
}

\begin{abstract}
Summary. In 5 caged langurs menstrual cycle length (for 125 cycles) varied from 18 to 45 days with a mean \pm s.d. of $26 \cdot 3 \pm 3.6$ days. Menstruation lasted for 2 days. A distinct cycle of vaginal smear cells was observed with a maximum cornification on Day 10 coinciding with the serum oestradiol peak. A monophasic pattern of vaginal temperature with a significant nadir on Day 11, 1 day after the oestradiol peak, was observed. Serum sialic acid concentrations directly reflected the oestrogenic activity and showed a significant peak on Day 10, coinciding with the oestradiol peak and was followed by a progesterone rise. Langurs menstruated throughout the year without showing any sign of summer amenorrhoea. We suggest that maximum cornification, vaginal temperature nadir and serum sialic acid peak could be used as markers for prediction and detection of the time of ovulation in langur monkeys.
\end{abstract}

Keywords: langur; vaginal temperature; serum oestradiol; vaginal smear patterns; serum sialic acid; ovulation; menstrual cycle

\section{Introduction}

Four species of langurs (Presbytis) are commonly available in India (Ramaswami, 1977); these are $P$. entellus, $P$. geei, $P$. johnii and $P$. pileatus. Certain aspects of the behavioural studies of these animals have been described by Jay (1965), Sugiyama et al. (1965) and Poirier (1969). The gross anatomy and histology of the female reproductive tract of the hanuman langur (Presbytis entellus) (David \& Ramaswami, 1971) have been reported. However, there is very little information on the reproductive endocrine and exocrine profile of this non-human primate.

This study was undertaken to acquire basic information on the changes in the gonadal hormones during the normal menstrual cycle of langurs. Changes in serum sialic acid levels, vaginal smear cytology and basal body temperature were also studied during the menstrual cycle to determine whether the changes in these characteristics could help to predict the time of ovulation.

\section{Materials and Methods}

Animals. Five adult female langur monkeys, weighing between 10 and $14 \mathrm{~kg}$, were caught from places around Jaipur, India. Animals were housed individually in steel cages (measuring $0.75 \times 0.75 \times 1.05 \mathrm{~m}$ ) under natural temperature and daylight conditions. Animals were fed with green leaves, roasted or soaked grams, bread, vegetables and fruits. Water was provided ad libitum.

Animals were quarantined for a period of 2 months before the study was started. During this period, they were acclimatized to laboratory conditions and were also trained for the taking of vaginal smears and blood samples. 
Collection of vaginal smears. Daily vaginal smears were obtained by using a sterile glass dropper after restraint of the animals for about $5 \mathrm{~min}$ in the cage. Slides stained with Papanicolaou stain (Riley et al., 1955) were examined for various cell types (Boris, 1940).

Recording of vaginal temperature. Vaginal temperature was recorded with the aid of a veterinary thermometer throughout the menstrual cycle.

Blood samples. Blood samples were collected daily throughout the menstrual cycle from the saphenous vein. Blood sampling was repeated over five alternate cycles of each animal. Serum was separated and stored at $-20^{\circ} \mathrm{C}$ until processed for hormone estimation.

To avoid stress to the animal due to repeated handling, the recording of vaginal temperature, and collection of vaginal smear and of blood samples were done simultaneously around 08:00 $\mathrm{h}$.

Estimation of sialic acid. Serum concentrations of sialic acid were estimated by using the method described by Warren (1959).

Estimation of gonadal hormones. Serum concentrations of oestradiol-17 $\beta$ and progesterone were assayed in triplicate by the specific radioimmunoassay (RIA) methods described in the W.H.O. Method Manual (WHO, 1981). In brief, oestradiol-17 $\beta$ was measured by using an antiserum raised against oestradiol-6(O-carboxymethyl)-oxime-bovine serum albumin and $\left[1,2,6,7-{ }^{3} \mathrm{H}\right]$ oestradiol (sp. act. $92 \mathrm{Ci} / \mathrm{mmol}$ ) as tracer. Antiserum raised against progesterone- 11 -succinylBSA and $\left[2,4,6,7-{ }^{3} \mathrm{H}\right]$ progesterone (sp. act. $94 \mathrm{Ci} / \mathrm{mmol}$ ) as tracer were used for the estimation of progesterone concentrations. The separation of free steroid from the bound was achieved by using dextran-coated charcoal suspension. The inter- and intra-assay coefficients of variation were, respectively, $10.0 \%$ and $3.6 \%$ for the oestradiol assay and $11 \cdot 5 \%$ and $4 \cdot 7 \%$ for the progesterone assay. The sensitivities of the assay methods were 15 pmol oestradiol and $30 \mathrm{pmol}$ progesterone.

Because of variations in cycle length, the results were analysed and centred according to the day of the oestradiol peak which served as the reference point and was designated as Day 0.

Analysis of results. The values for samples were determined from the best-fit straight line of the standard curve, linearized on logit-log co-ordinates by using a Hewlett-Packard Mini Computer (Model 9831A). The results on different days of the menstrual cycles were compared by using Student's $t$ test.

\section{Results}

\section{Menstrual cycle record}

Over a 2-year period the 5 langurs had 125 menstrual cycles. The cycle length varied between 18 and 45 days with a mean ( \pm s.d.) of $26 \cdot 3 \pm 3 \cdot 6$ days. The median length was 22 days (Fig. 1). The duration of menses ranged from 1 to 3 days with a mean of $2 \cdot 0 \pm 0 \cdot 1$ days. The animals menstruated throughout the year and showed no sign of amenorrhoea.

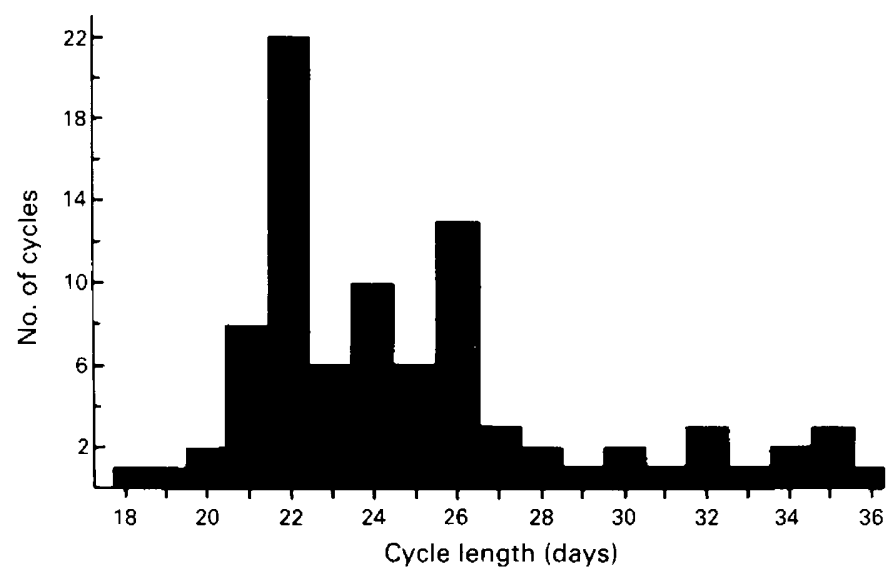

Fig. 1. Frequency distribution of menstrual cycles in langurs. 


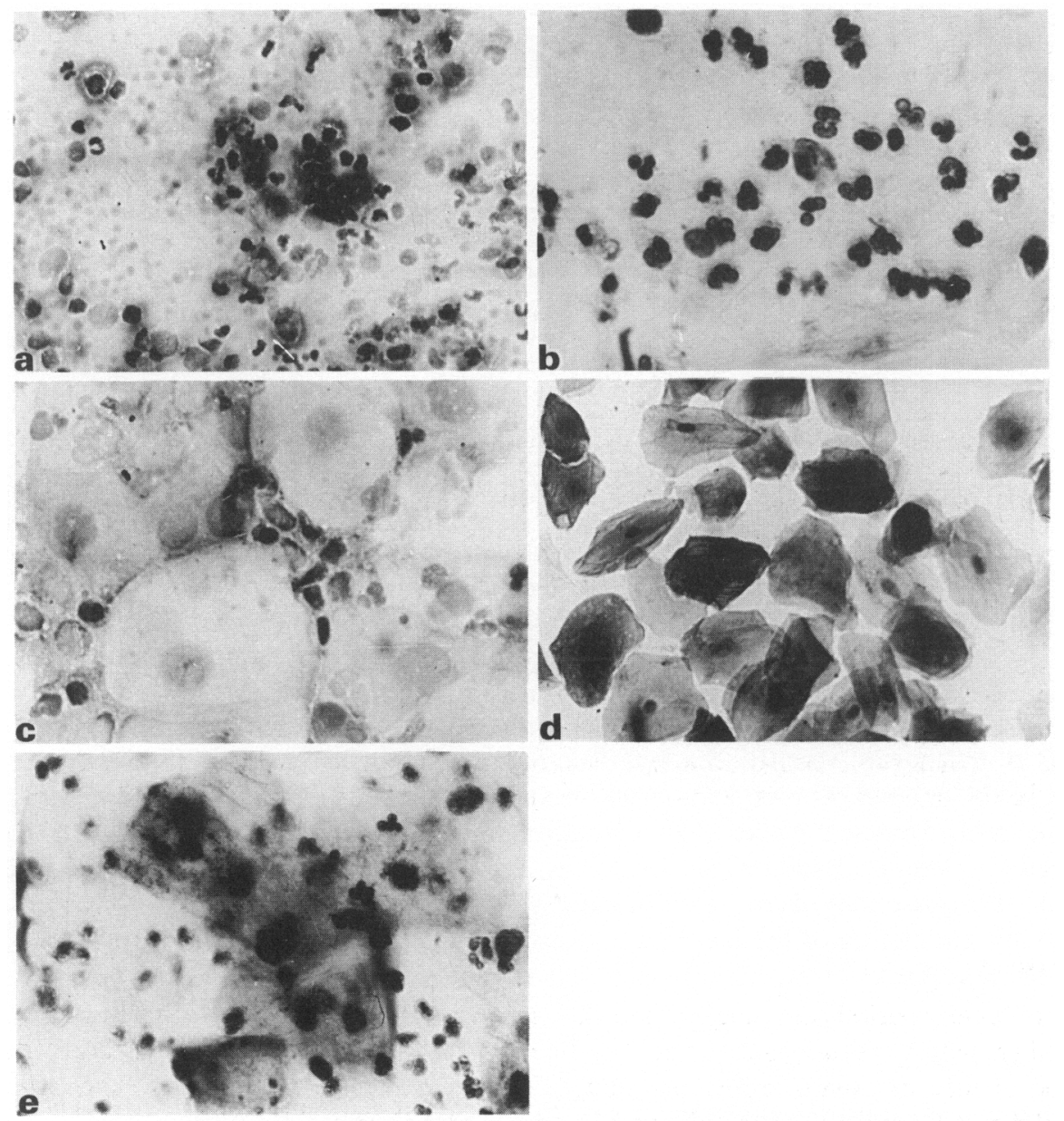

Fig. 2. Vaginal smear cytology during different phases of the menstrual cycle in langurs: (a) menstrual phase: $\times 170$; (b) post-menstrual phase: $\times 170$; (c) follicular phase: $\times 170$; (d) ovulatory phase: $\times 170$; (e) luteal phase: $\times 170$.

\section{Vaginal smear cytology}

On the basis of vaginal smear cell morphology different phases of the menstrual cycle were distinguished and their characteristics (Fig. 2) are as follows.

Menstrual phase. A 'thin' vaginal smear with considerable blood and mucus was observed. Large numbers of leucocytes with few epithelial and cornified cells were also noticed (Fig. 2a). Menses lasted for 1-3 days.

Post-menstrual phase. Proliferation of the vaginal mucosa was just beginning and the leucocytes were predominant (Fig. 2b). This phase lasted for 2-3 days.

Follicular phase. The follicular-phase smear was characterized by large epithelial cells with a large oval shaped nucleus and few leucocytes (Fig. 2c). This phase ranged from 3 to 4 days.

Preovulatory phase. During this phase, lasting 2 days, epithelial cells were progressively more cornified.

Ovulatory phase. There was marked desquamation of cornified cells, which had a degenerated nucleus or were enucleated. Leucocytes were almost absent. The cornified cells tended to remain separate from each other during this phase (Fig. 2d) which ranged from 2 to 3 days. 


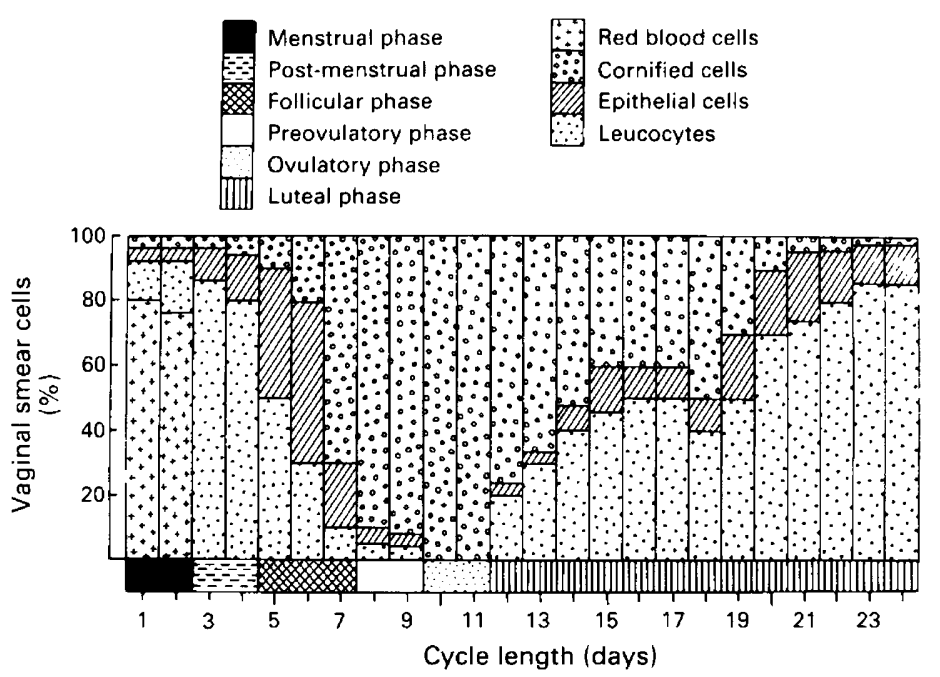

Fig. 3. Percentage distribution of vaginal cell types in the vaginal smear.

Luteal phase. Clumping and folding of cornified cells and an abrupt appearance of large numbers of leucocytes were the characteristic features of the early luteal phase. After 2-3 days, reversal of the process of cornification was noticed. The nuclei of the cells became progressively large and more vesicular whereas the cytoplasm was progressively less keratinized. The smear continued to contain abundant cornified cells, epithelial cells and large numbers of leucocytes (Fig. 2e). This phase ranged from 8 to 14 days.

A composite picture of the percentage distribution of various cell types in the vaginal smear during different phases of the menstrual cycle is shown in Fig. 3.

\section{Vaginal temperature}

Vaginal temperature ranged from 37.9 to $39.5^{\circ} \mathrm{C}$ on different days of the cycle. No significant difference in mean vaginal temperature during the follicular phase $\left(38.79 \pm 0.46^{\circ} \mathrm{C}\right)$ and the luteal phase $\left(38.74 \pm 0.43^{\circ} \mathrm{C}\right)$ was observed. However, a significant drop $\left(0.50^{\circ} \mathrm{C}\right)$ in the vaginal temperature was observed during the ovulatory phase in $84 \%$ of the cycles. The drop in the temperature was observed between Days 9 and 13 of the cycle. In $40 \%$ of the cycles, the temperature drop was on Day 11 (Fig. 4).

\section{Sialic acid concentrations}

Serum concentrations of sialic acid did not show any marked variation on different days of the follicular phase. The mean values were $22.1 \pm 0.3 \mathrm{mg} / 100 \mathrm{ml}$ (range $21 \cdot 2-22.5 \mathrm{mg} / 100 \mathrm{ml}$ ). However, between Days 8 and 11 of the cycle, an increase in the values was observed which lasted for 1 day. The mean peak levels were $23.6 \pm 0.3 \mathrm{mg} / 100 \mathrm{ml}$ (range $23.0-24.0 \mathrm{mg} / 100 \mathrm{ml}$ ). Thereafter, a sharp decline in the concentrations occurred. In $67 \%$ of the menstrual cycles the peak was observed on Day 10. After the mid-cycle peak, the concentrations of sialic acid during the luteal phase were lower than those observed during the follicular phase (Fig. 4).

\section{Oestradiol concentrations}

A gradual increase in the serum concentrations of oestradiol was observed during the follicular phase before the peak levels were attained between Days 8 and 11 of the cycle. In $49 \%$ of the cycles, 


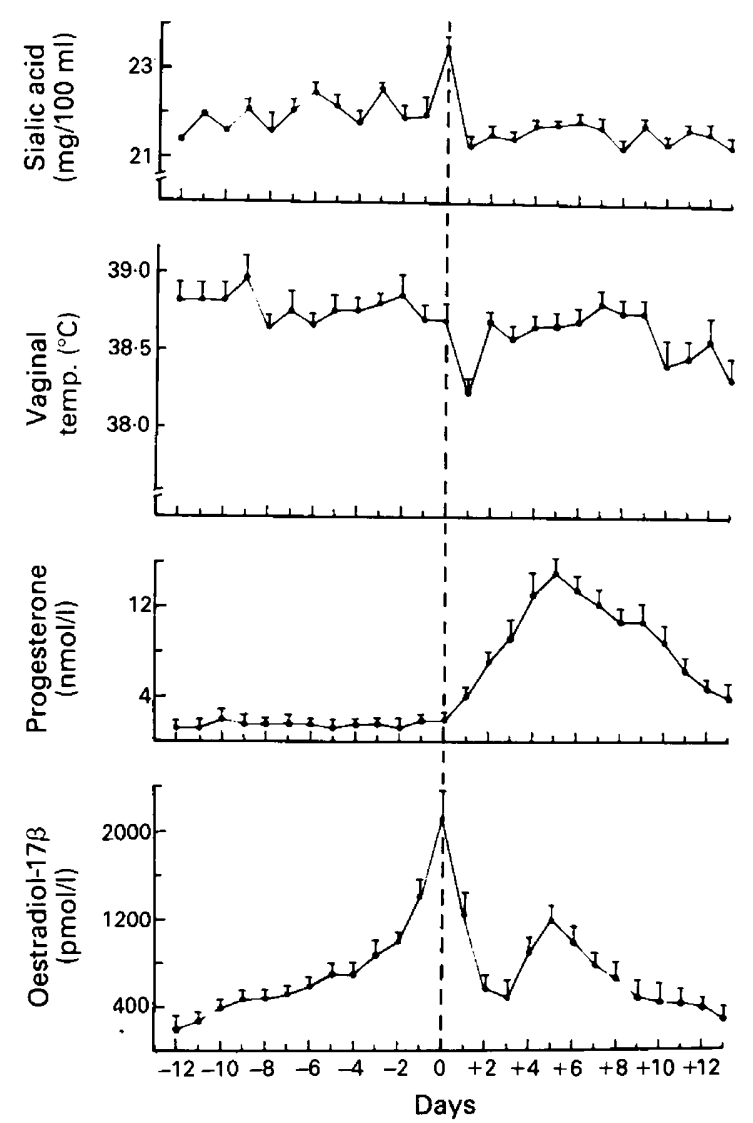

Fig. 4. Serum concentrations (mean \pm s.e.m.) of oestradiol, progesterone and sialic acid and vaginal temperature during the menstrual cycle. Day $0=$ day of oestradiol peak.

the major oestradiol peak was on Day 10 of the cycle. During Days 1-6 of the cycle, concentrations were $<600 \mathrm{pmol} / \mathrm{l}$. The mean peak values were $2116 \pm 217 \mathrm{pmol} / 1$ (range $1792-2620 \mathrm{pmol} / \mathrm{l})$. After the mid-cycle peak, a sharp decline in the oestradiol concentrations occurred. Between Days 12 and 14 of the cycle the levels had dropped to $410 \mathrm{pmol} / \mathrm{l}$, but a second rise $(1200 \pm 120 \mathrm{pmol} / \mathrm{l})$ occurred 4-6 days after the main oestradiol peak (Fig. 4).

\section{Progesterone concentrations}

There was no significant change in the serum progesterone values on different days of the follicular phase. Concentrations until the day of the oestradiol peak were $<1.8 \mathrm{nmol} / 1$ (range $1.09-1.74 \mathrm{nmol} / \mathrm{l})$. There was then a gradual rise in the progesterone values and peak levels (mean $13.5 \pm 1.7 \mathrm{nmol} / 1$, range $12.6-20.7 \mathrm{nmol} / \mathrm{l})$ were attained between Days 13 and 19 of the cycle. In each ovulatory cycle, concentrations of $10 \mathrm{nmol} / 1$ or more were observed for at least 3 consecutive days. Thereafter a gradual decrease in the progesterone values was observed (Fig. 4).

\section{Anovulatory cycles}

In 4 menstrual cycles (one in each of 4 animals), blood concentrations of oestradiol and progesterone were indicative of anovulation (Fig. 5). The mean cycle length was $42.0 \pm 3$ days (range $40-45$ days). Oestradiol concentrations during the follicular phase were $2.6 \pm 0.6 \mathrm{pmol} / 1$ and the 


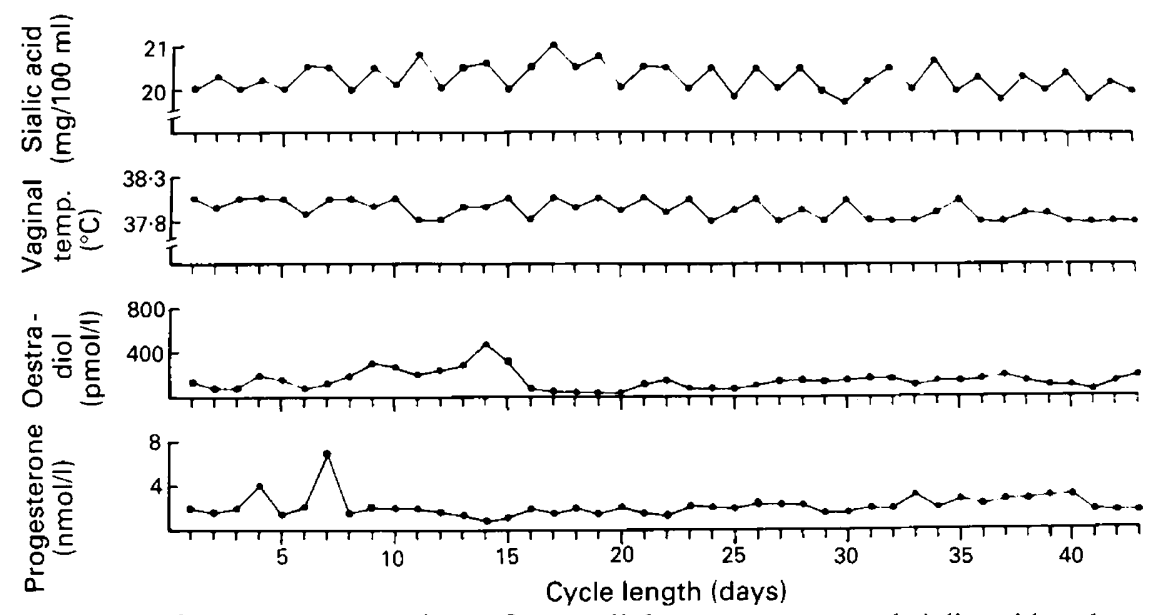

Fig. 5. Pattern of serum concentrations of oestradiol, progesterone and sialic acid and vaginal temperature during 4 anovulatory cycles of langurs.

mid-cycle oestradiol peak was not detected (Fig. 5). Similarly, there was no marked rise in the serum progesterone concentrations at the anticipated time of the luteal phase (Fig. 5).

The mid-cycle rise in serum sialic acid concentrations (Fig. 5) and the drop in vaginal temperature (Fig. 5) were also not evident in these anovulatory cycles. Leucocytes were predominant in the vaginal smear throughout the cycle.

\section{Discussion}

This study indicates that the menstrual cycle length, duration of menses and the pattern of endocrine profile of gonadal hormones during the menstrual cycle of langur are very similar to those reported for other commonly used species of non-human primates and women (Boris, 1940; Jenson, 1967; Hutchinson, 1970; Moghissi, 1976, 1980; Graham et al., 1977; Anand Kumar et al., 1980; Murty et al., 1980; Varavudhi \& Yodyingyuad, 1980; Bauman, 1981; Aksel, 1981). The changes in vaginal cell cytology, vaginal temperature and in the serum sialic acid levels during the menstrual cycle coincide with the changes in the gonadal hormones.

Six phases of menstrual cycle described in langur are similar to that reported for women (Boris, 1940), squirrel monkey (Rosenblum et al., 1967; Hutchinson, 1970), cynomolgus monkey (Varavudhi \& Yodyingyuad, 1980) and rhesus monkey (David \& Mastroianni, 1968; Anand Kumar et al., 1980).

Cyclic changes in the cervical mucus are known to reflect the hormonal changes associated with menstrual cycle (Moghissi et al., 1972). Maximum cornification and increased quantity of clear cervical mucus during the ovulatory phase have been correlated with oestrogen and pregnanediol excretion and serum concentrations of LH, FSH, oestradiol and progesterone (Pauerstein et al., 1978; Marishita et al., 1979). Maximum number of cornified cells during the oestradiol peak was followed by a progesterone rise, and absence of distinct changes in the vaginal cytology in the anovulatory cycles indicates that the vaginal smear cytology can be used as a marker for the occurrence of ovulation in langur monkeys.

The monophasic pattern of basal body temperature observed during the normal ovulatory menstrual cycle of langurs in this study was similar to that reported earlier (David, 1968; Shandilya, 1974). However, the pattern of the basal body temperature in the langur differs from that reported for some other non-human primate species (Hendrickx et al., 1967; Balin \& Wan, 1968; Graham et al., 1977). In these animals after a temperature drop, which probably coincides with the oestrogen 
peak, a sharp and significant rise in temperature was observed during the luteal phase. This rise is probably due to an increase in the production and secretion of noradrenaline which is a thermogenic neural hormone (Moghissi, 1980; Newill \& Mauricekatz, 1982). In women, although the biphasic pattern is more common (Moghissi, 1980; Newill \& Mauricekatz, 1982), some ovulatory cycles a monophasic pattern has also been reported (Moghissi, 1976; Lenton et al., 1977; Moghissi, 1980; Bauman, 1981). The reason for the absence of a thermogenic response to ovulatory levels of progesterone in the langur and in women is not known. Nevertheless, the drop in basal body temperature observed in langurs is very similar to that reported for chimpanzees (Graham et al., 1977) and women (Davis \& Fugo, 1948; Israel \& Schneller, 1950) and it provides an indication of occurrence of ovulation. Absence of a significant drop in temperature in the anovulatory cycles further supports this observation.

A significant rise in the serum sialic acid concentrations coincides with the major oestradiol peak. This pattern of sialic acid in the circulation is similar to the urinary excretion of sialic acid in langurs (Shandilya et al., 1977) and in women (Jenson, 1967). A role for oestrogen in maintaining sialic acid levels of the genital organs has been suggested for ovariectomized langur monkeys (Shandilya et al., 1977). However, progesterone has been reported to suppress the sialic acid contents (Coppola \& Ball, 1966). The high progesterone concentrations during the luteal phase explain the low levels of sialic acid and absence of a secondary sialic acid peak. Absence of a sialic acid peak during the anovulatory cycle increases the importance of serum sialic acid measurement for ovulation detection in the langur.

The changes in circulating concentrations of oestradiol and progesterone during the menstrual cycle of langurs are, in general, similar to those described for bonnet monkeys (Stabenfeldt \& Hendrickx, 1972; Murty et al., 1980), rhesus monkeys (Hotchkiss et al., 1971; Hodgen et al., 1976; Anand Kumar et al., 1980), baboons (Goncharov et al., 1976; Koyama et al., 1977; Raykling \& Westfahl, 1978), chimpanzees (Graham et al., 1972; Reyes et al., 1975; Graham et al., 1977) and women (Landgren et al., 1980; Aksel, 1981). However, the occurrence of a secondary oestradiol peak may bring the langur pattern closer to that of the human than to rhesus and baboon.

We suggest that langur monkeys would be useful for studying aspects of reproduction at basic levels and long-term testing of contraceptives as models for human reproduction.

The work was funded by the Indian Council of Medical Research, New Delhi, India. We thank WHO for the supply of RIA reagents.

\section{References}

Aksel, S. (1981) Hormonal characteristics of long cycles in fertile women. Fert. Steril. 36, 521-523.

Anand Kumar, T.C., David, G.F.X., Sharma, D.N., Puri, C.P., Puri, V., Dubey, A.K., Sehgal, A., Sankaranarayanan, A. \& Pruthi, J.S. (1980) Reproductive profile of the rhesus monkey with reference to the testing of contraceptives. In Non-Human Primate Models for Study of Human Reproduction, pp. 37-49. Ed. T. C. Anand Kumar. Karger, Basel.

Balin, H. \& Wan, L.S. (1968) The significance of circadian rhythm in the research for the moment of ovulation. Fert. Steril. 19, 228-243.

Bauman, J.E. (1981) Basal body temperature: unreliable method of ovulation detection. Fert. Steril. 36, $729-733$.

Boris, B.R. (1940) The vaginal smear-basal body temperature technic and its application to the study of functional sterility in women. Endocrinology 27, $843-856$.

Coppola, J.A. \& Ball, J.L. (1966) Uterine sialic acid in relation to ovarian steroids. Steroids $\mathbf{8}, 345-352$.

David, A. \& Mastroianni, L., Jr (1968) Cervical mucus arborization in the rhesus monkey. J. Reprod. Fert. 17, 495-499.

David, G.F.X. (1968) Some aspects of endocrine control of reproduction in the Indian Hanuman Langur (Presbytis entellus entellus). Ph.D. thesis, University of Rajasthan, India.

David, G.F.X. \& Ramaswami, L.S. (1971) Reproductive system of the North Indian langur (Presbytis entellus entellus). J. Morph. 135, 99-130.

Davis, M.E. \& Fugo, N.W. (1948) The cause of physiological basal temperature changes in women. $J$. clin. Endocr. Metab. 8, 550-563.

Goncharov, N., Aso, T., Cekan, Z., Pachalia, N. \& Diczfalusy, E. (1976) Hormonal changes during the menstrual cycle of the baboon (Papio hamadryas). Acta endocr., Copenh. 82, 396-412.

Graham, C.E., Collins, D.C., Robinson, H. \& Preedy, J.R.K. (1972) Urinary levels of estrogen and 
pregnanediol and plasma levels of progesterone during the menstrual cycle of the chimpanzee: relationship to the sexual swelling. Endocrinology 91, 13-24.

Graham, C.E., Warner, H., Misener, J., Collins, D.C. \& Preedy, J.R.K. (1977) The association between basal body temperature, sexual swelling and urinary gonadal hormone levels in the menstrual cycle of the chimpanzee. J. Reprod. Fert. 50, 23-28.

Hendrickx, A.G., Claborn, L.D., Laenger, C.J., Suhler, S.A. \& Ware, R.W. (1967) Continuously telemetred vaginal temperature in the baboon. In Baboon in Medical Research, Vol. II, pp. 419-435. Ed. M. Vagtborg. University of Texas Press, Austin.

Hodgen, G.D., Wilks, J.W., Vaitukaitis, J.L., Chen, H.C., Papkoff, H. \& Ross, G.T. (1976) A new radioimmunoassay for follicle-stimulating hormone in macaques: ovulatory menstrual cycles. Endocrinology 99, 137-145.

Hotchkiss, J., Atkinson, L.E. \& Knobil, E. (1971) Time course of serum estrogen and luteinizing hormone (LH) concentrations during the menstrual cycle of the rhesus monkey. Endocrinology 89, 177-183.

Hutchinson, T.C. (1970) Vaginal cytology and reproduction in the squirrel monkey (Saimiri sciureus). Folia primatol. 12, 212-223.

Israel, S.L. \& Schneller, O. (1950) The thermogenic property of progesterone. Fert. Steril. 1, 53-65.

Jay, P.C. (1965) The common langur of North-India. In Primate Behaviour, pp. 197-249. Ed. I. De Vore. Holt, Rinehart \& Winston, New York.

Jenson, D.R. (1967) Distribution of sialic acid in selected tissue and body fluid during the female reproductive cycle. Biol. Reprod. 11, 349-355.

Koyama, T., deLapena, A. \& Hagino, N. (1977) Plasma estrogen, progestin and luteinizing hormone during the normal menstrual cycle in the baboon: role of luteinizing hormone. Am. J. Obstet. Gynecol. 127, $67-72$.

Landgren, B.M., Unden, A.L. \& Diczfalusy, E. (1980) Hormonal profile of the cycle in 68 normally menstruating women. Acta endocr., Copenh. 94, 89 98.

Lenton, E.A., Weston, G.A. \& Cooke, I.D. (1977) Problems in using basal body temperature recording in an infertility clinic. Br. med. $J$. 1, 803-805.

Marishita, H., Hashimato, T., Mitani, H., Tanaka, T., Higuchi, K. \& Ozra, T. (1979) Cervical mucus and prediction of the time of ovulation. Gynecol. Obstet. Invest. 10, 157-162.

Moghissi, K.S. (1976) Accuracy of basal body temperature for ovulation detection. Fert. Steril. 27, 1415-1421.

Moghissi, K.S. (1980) Prediction and detection of ovulation. Fert. Steril. 34, 89-98.

Moghissi, K.S., Syner, F.N. \& Evans, T.N. (1972) A composite picture of the menstrual cycle. Am. J. Obstet. Gynecol. 114, 405-418.

Murty, G.S.R.C., Ramasharma, K., Mukku, V.R., Srinath, B.R. \& Moudgal, N.R. (1980) Reproductive endocrinology of bonnet monkeys. In Non-Human Primate Models for Study of Human Reproduction, pp. 50-54. Ed. T. C. Anand Kumar. Karger, Basel.

Newill, R.G.D. \& Mauricekatz, F.C.P. (1982) The basal body temperature chart in artificial insemination of donor pregnancy cycles. Fert. Steril. 38, 431-438.

Pauerstein, C.J., Eddy, C.A., Croxatto, D.H., Hess, R., Silerkhoda, T.M. \& Croxatto, H.B. (1978) Temporal relationship of estradiol, progesterone and $\mathrm{LH}$ levels to ovulation in women and infra human primates. Am. J. Obstet. Gynecol. 130, 876-886.

Poirier, F.E. (1969) The Nilgiri-langur (Presbytis johnii) troop. Its composition, structure, function and change. Folia primatol. 10, 20-47.

Ramaswami, L.S. (1977) Reproductive biology of the langur monkey (Presbytis entellus entellus Dufresne). In Use of Non-Human Primate in Biomedical Research, pp. 110-120. Eds M. R. N. Prasad \& T. C. Anand Kumar. Indian National Science Academy, New Delhi.

Raykling, O. \& Westfahl, P.K. (1978) Steroid changes during the menstrual cycle of the baboon (Papio cynocephalus) and human. Biol. Reprod. 18, 392-400.

Reyes, F.I., Winter, J.S.D., Feiman, C. \& Hobson, W.C. (1975) Serial serum levels of gonadotropins, prolactin and sex steroids in the nonpregnant and pregnant chimpanzee. Endocrinology 96, 1447-1455.

Riley, G.M., Dontar, E. \& Gill, B. (1955) Use of serial vaginal smear in detecting time of ovulation. Fert. Steril. 6, 86-102.

Rosenblum, L.A., Nathan, T., Nelson, J. \& Kaufman, I.C.H. (1967) Vaginal cornification cycle in the squirrel monkey (Saimiri sciureus). Folia primatol. 6, 83-91.

Shandilya, L.N. (1974) Some aspects of biochemical and histological studies of the reproductive cycle in the Indian Hanuman langur (Presbytis entellus entellus Dufresne). Ph.D. thesis, University of Rajasthan, India.

Shandilya, L.N., Ramaswami, L.S. \& Shandilya, N. (1977) Sialic acid concentration in the reproductive organs, pituitary gland and urine of the Indian langur monkey (Presbytis entellus entellus Dufresne). $J$. Endocr. 73, 207-213.

Stabenfeldt, G.H. \& Hendrickx, A.G. (1972) Progesterone levels in the bonnet monkey (Macaca radiata) during the menstrual cycle and pregnancy. Endocrinology 91, $614-619$.

Sugiyama, Y., Yoshiba, K. \& Parthasarathy, M.D. (1965) Home range, mating season, male groups and intertroop relation in Hanuman langur (Presbytis entellus). Primates 6, 73-106.

Varavudhi, P. \& Yodyingyuad, V. (1980) Hormonal changes during the menstrual cycles in the crab eating monkey, M. fascicularis. In Non-Human Primate Models for Study of Human Reproduction, pp. 55-60. Ed. T. C. Anand Kumar. Karger, Basel.

Warren, L. (1959) Sialic acid in human semen and male genital tract. $J$. clin. Invest. 38, 755-761.

WHO Method Manual (1981) Programme for the Provision of Matched Assay Reagents for the Radioimmunoassay of Hormones in Reproductive Physiology. In WHO Special Programme of Research, Development and Research Training in Human Reproduction, 5th edn. World Health Organization, Geneva.

Received 28 April 1987 